\title{
ITEM in Botswana and Uganda
}

\author{
R. Bisaso, O. Kereteletswe, I.D. Selwood, A.J. Visscher \\ Department of Higher Education, Makerere University. MoE, Botswana. School of Education, \\ University of Birmingham. Faculty of Behavioural Sciences, University of Twente
}

\begin{abstract}
This article reports on the lessons learnt from the implementation of a computerized information system (CIS) for managing human resources at the Ministry of Education in Botswana, and on the usage of CISs in the management of secondary schools in Uganda. The findings from these African studies portray the levels of usage, their impact and the critical success factors that most influence the utilization of the CISs. In both countries, clerical usage of the CISs was reported. User training is reported as the most important determinant of CIS usage in both Uganda and Botswana. In Uganda, managerial usage by school managers is very limited, but users are generally positive concerning the effects of CISs use. In Botswana, the direct usage by managers is also limited as is use for decision-making. It is concluded that wider and better CIS usage can be promoted by carefully designed user training, grounded on a thorough analysis of the needs of the user group.
\end{abstract}

Keywords: Developing countries, management information systems, educational management

\section{INTRODUCTION}

Over the last two decades, the use of management information systems for education has grown enormously in the industrialized countries and now developing countries are starting to utilize the potential of these systems. Administrative reforms in Botswana geared to improving efficiency in the public sector together with a rapidly expanding education systems are the foundation upon which the computerization of the activities of the Ministry of Education (MOE) were grounded. The aim of the introduction of a computerized personnel management systems was provision of adequate and accurate staff information for management reporting and planning purposes. In Uganda, since the inception of universal primary education (UPE) in 1997, enrolments in secondary schools have increased greatly as a result of the escalating primary school leavers. For example, in 1999, Uganda had

Please use the following format when citing this chapter:

Bisaso, R., Kereteletswe, O., Selwood, I.D. and Visscher, A.J., 2007, in IFIP International Federation for Information Processing, Volume 230, Knowledge Management for Educational Innovation, eds. Tatnall, A., Okamoto, T., Visscher, A., (Boston: Springer), pp. 179-186. 
only 625 registered secondary schools but by 2001 , the number of registered secondary schools had risen to 1850 (Aguti, 2002). Owing to this exponential effect of UPE, secondary schools have now started utilizing the potential that computerised information systems (CISs) offer. In this paper we report on studies carried out in Uganda and Botswana respectively, that provide insight into how these two developing countries benefit from the potential of ICT for administering and managing education, which problems they meet, and which are the critical success factors for implementing CISs.

\section{RESEARCH QUESTIONS AND RESEARCH FRAMEWORK}

The two studies were guided by the following research questions, which were formulated with regard to the variable clusters in the Visscher model $(1996 ; 2001$, see Figure 1).

1. To what extent and how are the computerized information systems used in secondary schools and in the Ministry of Education in Uganda and Botswana respectively?

2. What are the positive/negative effects of the use of the computerized information systems on managerial activities in secondary schools and in the Ministry of Education?

3. What problems are faced in the introduction and utilization of computerized information systems in these two developing countries?

4. Which factors influence the utilization of the computerized information systems in these two developing countries?

Figure 1 reflects the assumption that the extent of usage of a CIS depends on the influence of CIS quality, implementation process features and organizational features. Therefore, it is expected that the higher the perceived CIS quality, the more the implementation process promotes CIS usage, and the stronger the correspondence between CIS features and the nature of the organization, the more intense CIS use (block D) will be. The extent and nature of CIS use may yield both positive and negative effects (block E). While there has been extensive application of the Visscher model in research in the developed countries (Visscher 1996; 2001), its application in developing countries has been exploited for the first time in the studies that we report on here. 


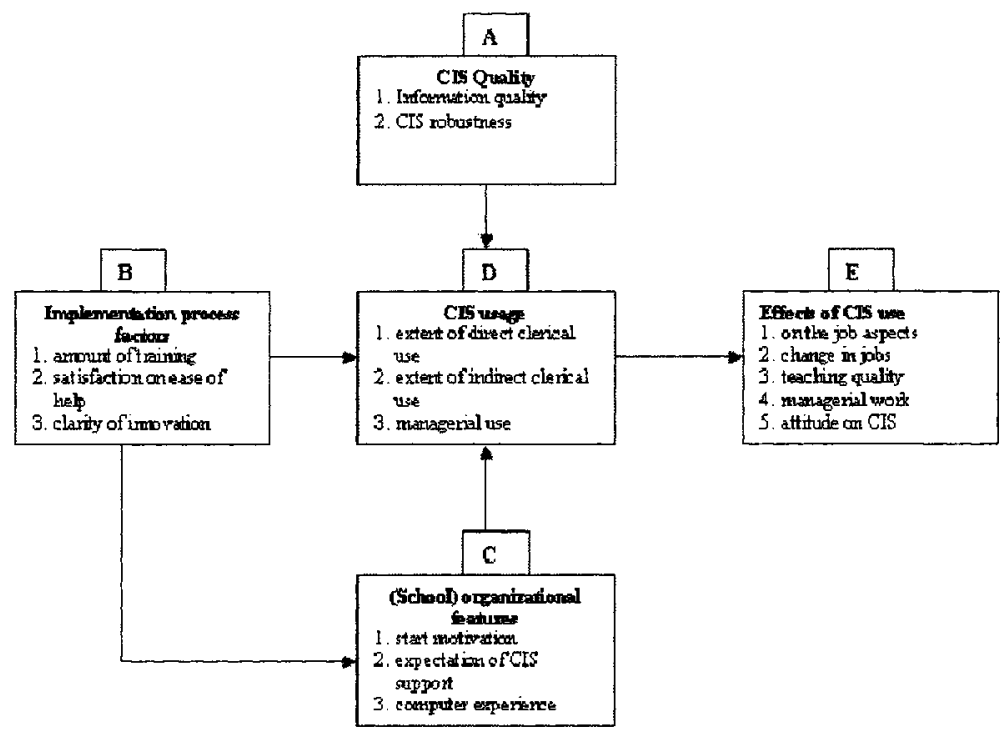

Figure 1: Factors influencing the usage and impact of CIS in developing countries (Visscher 1996 and 2001)

\section{METHOD AND DATA ANALYSIS}

The study in Uganda was carried out in the four school districts that have the biggest and most well developed schools. The implementation of Information Technology and Educational Management (ITEM) is recent and therefore it was felt best to evaluate schools where the probability of ITEM's occurrence would be greatest. Fifty-five schools were selected to participate in the study using a non-probability sampling method. Respondents were school management personnel (one per school). The user response rate was $100 \%$ after follow-up activities. Thirty-four schools reported that they were CIS-users and the other 21 schools indicated that they either had an information system but were reluctant to use it, or they were in the advanced stages of acquiring one.

In Botswana, 168 questionnaires were distributed to the departments involved in the management of teachers at the Ministry of Education. These were Teaching Service Management, Secondary Education, Primary Education, and Regional Education Offices. The response rate was $76 \%$. Respondents included clerks, middle managers and senior managers.

Data analysis involved the computation of frequencies and carrying out regression analyses, the latter to establish those factors that predict the level 
of direct and indirect information system use by school management staff in Uganda and by staff of the MOE in Botswana.

\section{RESULTS}

\subsection{The Ugandan study}

\subsubsection{CIS use}

Utilization of the CISs was both direct and indirect. In Ugandan schools $60 \%$ of school managers used their CIS directly for one to ten hours per month. However, $66 \%$ of managers reported indirect use of greater than eleven hours. Thus it would appear that schools managers prefer their staff to retrieve information from the CIS for them.

The analysis of the questionnaire returns showed that the most common CIS modules in Ugandan secondary schools were financial monitoring and planning $(91 \%)$, student records $(90 \%)$ and student assessment $(83 \%)$. Commencing CIS implementation with financial planning and monitoring and pupil records was also common in developed countries (Selwood 1995), and this is probably due to managers being concerned regarding their liability if financial records are found to be inaccurate. Furthermore, school funding generally relates to pupil numbers, and age of pupils, therefore pupil data is needed by the finance module (and for future implementation of most other modules). The least available modules were library management and student attendance.

\subsubsection{Effects of CIS use}

Over half the respondents were positive about the effects of CIS usage. The highest level of response concerned 'evaluation of school performance' with $81 \%$ feeling this had improved. Interestingly, this effect 'evaluation of school performance' did not record any negative response. 'Utilization of school resources' had $74 \%$ of staff reporting improvement and 'information for curriculum planning' was reported improved by $69 \%$ of respondents. 'Stress' and 'workload' are reported to have improved according to $66 \%$ and $69 \%$ of the respondents respectively, thus staff feel less stressed and that their workload has reduced. Only 'internal communication with colleagues' registered a significant negative percentage $(23 \%)$. However even for this category, $55 \%$ were positive that there were benefits.

\subsubsection{Problems}

Even though positive effects of implementing the schools' CISs were reported in the previous section, the quality of the CIS failed to meet the expectations of many users with $62 \%$ of the respondents noting that the systems did not fully provide the information they needed. Furthermore, the 
expectations of the systems exceeded the most optimistic projections of them e.g. $69 \%$ of the respondents felt the quality of teaching had been influenced by the CIS. This remains to be empirically proven especially without any established relationship between the schools' clerical work and the teaching and learning process. Lack of prior experience in using computers either at home or work was very evident from the respondents but this is perhaps a symptom of the lack of use of information technology in developing countries.

\subsubsection{Critical Success factors}

The results of regression analysis of the data gathered in the Ugandan study demonstrates clearly that the "amount of external training" is a factor predicting system usage in secondary schools. 'Support from the system administrator' also plays an important role possibly due to the lack of experience of school managers, since information system utilization is a recent innovation in Uganda. Together both factors explain $35 \%$ of the variance in CIS use. Furthermore the analysis demonstrated if the 'amount of external training' increases by 1 standard deviation then CIS-use increases by .39 of a standard deviation. Interestingly, if 'support from system administrator' increases by 1 standard deviation CIS usage increases even more, by .61 of a standard deviation.

\subsection{The Botswana study}

\subsubsection{CIS use}

The analyse of questionnaire returns clearly showed that direct use of the CIS was not high in Botswana with $34 \%$ of respondents not using it directly and $59 \%$ using it directly for between 1 to 4 hours per week. Indirect use appears somewhat better with only $14 \%$ reporting no use and $73 \%$ reporting use between 1 to 4 hours per week. Further analysis of the data by type of user revealed that managers tended to be indirect users and clerical staff were more likely to be direct users (Kereteletswe and Selwood, 2004).

\subsubsection{Effects of CIS use}

Even though as detailed above CIS usage was not as high as would be expected the data gathered clearly demonstrates positive attitudes with respect -to the effects of CIS. Combining better and much better only 'processing gratuity' and 'processing terminal benefits' receive less than $50 \%$ positive response. The highest level of improvement was seen for 'management of teacher transfer' and 'errors in posting' both achieving $94 \%$. Interestingly there appears to be a contradiction in the results when we compare 'time needed to carry out duties' ( $88 \%$ reporting an improvement) with 'work load' ( $56 \%$ reporting an improvement). The reasons for this may be either that with the introduction of CIS some staff have had other duties added to their workload, or as Riggs (1964) asserts, in developing countries 
(prismatic societies) there is a tendency, when innovations are introduced, for the old and new to sit side by side. That is to say, the old system continues and runs in parallel with new, thus duplicating work, and increasing workload.

\subsubsection{Implementation constraints in Botswana}

Based on their experience of implementation at the Ministry, the respondents were asked to rank the potential implementation constraints likely to be faced by the MoE in rolling out the CIS to Regional Education Offices (REOs) and schools. The factors were ranked in order of priority with 1 (the most important) and 8 (the least important). The results of the Friedman test show that 'lack of technical support' and 'lack of resources' ranked 2.10 and 2.21 respectively. This suggests that the respondents viewed these two factors as highly probable problematic factors to be faced by the $\mathrm{MoE}$ in rolling out the CIS to REOs and schools.

\subsubsection{Critical success factors}

In Botswana, analysis was undertaken on factors that most determine the level of direct or indirect use. The variables age, qualification, and gender of respondents were not significantly explanatory of differences in extent of information system use. On the other hand, the division the respondent belonged to and the position of responsibility the respondent held, explained together both direct and indirect usage at a rate of $56 \%$ and $41 \%$.

Regression analysis showed that variance in the extent of information system use in Botswana was explained by the factors 'information quality' and 'amount of external training' for both direct and indirect use.

\section{CONCLUSION}

In Uganda, it is apparent that considerable progress has been made in implementing CIS in schools. However to optimise use it is equally apparent from the evidence presented here, that investment in external training for users is needed, and that as Systems Administrators are highly valued these need to be retained and supported. There are also some concerns regarding the quality of the CISs in use as respondents felt they did not fully meet their needs. However, respondents are generally optimistic and positive concerning the benefits of CIS usage in their schools.

In Botswana, after five years of system implementation, system utilization still appears somewhat ad hoc. Again external training and system quality seem to be factors that need to be addressed. Noteworthy, the factor training has been found significant in studies in the Netherlands, Hong Kong and the United Kingdom (Visscher and Bloemen, 1999; Visscher, Wild and Smith, 2003). In Botswana, it is apparent that system use has a relationship with the other cluster blocks in the Visscher model.

It is paramount that secondary schools and education ministries in developing countries like Uganda and Botswana design effective training 
programmes that will step up system usage. Visscher and Bloemen (2001) recommend that management-oriented training courses purposely developed for MIS usage ought to be evolved and tested to equip managers with skills necessary to bolster decision-making processes and the functioning of their institutions. Furthermore, Selwood and O'Mahony (2003) have developed a framework for ITEM competence that can be applied to develop training courses for various types of ITEM users.

Other factors that influence usage, and type of systems usage may well be cultural. The work of Riggs (1964) has already been noted in discussing system usage in Botswana and his theory may well account for some resistance to change or apparent inertia when change is implemented in developing countries. Furthermore, managers' attitudes, and work patterns may also influence system usage. Results of the analysis showed that senior management are more indirect than direct users of the CIS in Botswana, while low echelon positions use the system more directly. The literature on education management points to possible reasons why this may be the case. For example, Mintzberg (1989) asserts that managers prefer taking decisions rather than not taking them because at least something is done. Management literature, however suggests that many managers are not reflective planners and rely more on instant information received in informal ways (Visscher 1996). However, senior managers need readily available information on which to base their decisions (Visscher and Fung 2001). Thus, the lower echelon positions become information providers to the senior management.

Visscher (1996) reports that schools vary in their policy-making capacity and that the areas in which schools develop their policies often differ in degree. For example, a vibrant school policy could be developed over school resources like finance, buildings and other infrastructure while instructional matters like teaching methods, or even instructional content decisions are left to the discretion of the teachers. It is this divergence in policy-making capacity that will strongly impact on the implementation of information systems in school policy making. It is self evident that, the introduction of an information system in an area where a school has a limited policy will not improve policy-making capacity in that area, but instead precipitate additional problems associated with innovations without readiness. It is advisable that policy-making be first nurtured through organizational development prior to introduction of CIS. The usage and impact of a CIS can be extensive if schools developed a policy before installation of the CIS. It is also important that close scrutiny is made in relation to the outstanding organizational differences between schools.

To conclude, developing countries have now realized the potential that ITEM offers to the efficient and effective handling of information at both ministerial and school levels. Governments must understand that the change process is gradual and takes time; the implication being that investment in computerised information system usage should involve enough time for effective assimilation. Also, that investment in user training is essential if 
returns on investments in time, infrastructure and hardware are to be rewarded by effective use of CIS for Educational Management.

\section{REFERENCES}

Aguti, J.N. (2002). Facing up the challenge of UPE in Uganda through Distance Teacher Education programmes. Paper presented at Pan Commonwealth Forum on Open Learning; Transforming Education for development. Durban, South Africa.

Kereteletswe O.C., and Selwood I.D. (2005). Evaluation of the Implementation of Information Technology in Education Management (ITEM) in Botswana in Tatnall, A., Osario, J. and Visscher, A. (Eds.) Information Technology and Educational Management in the Knowledge Society. New York: Springer.

Mintzberg (1989). Mintzberg on Management. New York: Free Press.

Riggs Fred, W. (1964) Administration in Developing Countries: The Theory of Prismatic Society. Boston: Houghton

Selwood I. and O'Mahony C. (2003) Core Competences for ITEM - a model in Selwood, I.D., Fung, A.C.W., \& O'Mahony C. (Eds.) Management of Education in the Information Age - The Role of ICT. pp.195-201. Boston: Kluwer.

Selwood, I.D., (1995). The Development of ITEM in England and Wales. In Barta, B.Z., Telem, M., and Gev, Y. (Eds.), Information Technology in Educational Management pp.85-92. London: Chapman Hall for IFIP.

Visscher, A.J. (1996). The implications of how school staff handle information for the usage of school information systems. International Journal of Educational Research, 25 (4), 323-334.

Visscher, A.J. (2001). Computer-Assisted School Information Systems: the concepts, intended benefits, and stages of development. In Visscher, A.J., Wild, P. and Fung, A.C.W. (Eds.) (2001). Information Technology in Educational Management: Synthesis of Experience, Research and Future Perspectives on Computer-Assisted School Information Systems (pp. 3-18). Dordrecht: Kluwer.

Visscher, A.J. and Bloemen, P.P.M. (1999). Evaluation and use of computer-assisted management information systems in Dutch schools. Journal of Research on Computing in Education, 32(1), 172-188.

Visscher, A.J. and Bloemen, P.P.M. (2001). CSIS Usage in School Management: A Comparison of Good and Bad Practice Schools. In P. Nolan, A. Fung, and M. Brown (Eds.), Institutional improvement through information technology in educational management (pp. 87-97). London: Kluwer.

Visscher, A.J. and Fung A.C.W (2001). Imperatives for successful implementation of school information systems. In Visscher, A.J., Wild, P. and Fung, A.C.W. (Eds.) (2001). Information Technology in Educational Management: Synthesis of Experience, Research and Future Perspectives on Computer-Assisted School Information Systems (pp.115-133). Dordrecht: Kluwer.

Visscher, A.J., Wild, P., and Smith, D. (2003). The Results of Implementing SIMS in English Secondary schools. In Selwood, I.D, Fung, A.C.W., and O'Mahony C.D (Eds.)(2003). Management of Education in the Information Age. The Role of ICT (pp. 34-44). London: Chapman and Hall. 